\title{
Fulminant Adenocarcinoma of the Rectum with Hepatic Metastasis in a Young Pregnant Woman: A Case Report
}

\author{
Edward Araujo Júnior Felipe Favorette Campanharo \\ Sue Yasaki Sun Luciano Marcondes Machado Nardozza \\ Rosiane Mattar Antonio Fernandes Moron \\ Department of Obstetrics, São Paulo Federal University (UNIFESP), \\ São Paulo, Brazil
}

\section{Key Words}

Cancer of the rectum - Pregnancy - Metastasis - Magnetic resonance imaging · Microscopy

\begin{abstract}
Cancer is the second leading cause of death during the reproductive years, but the incidence during pregnancy is low. The incidence of cancer of the rectum during pregnancy is very rare (1:50,000 to 1:100,000 pregnancies). Usually, the symptoms of this type of cancer are nonspecific and sometimes they are confused with normal changes of pregnancy. The diagnosis of rectal cancer is usually made in the late stage of pregnancy. The treatment of this cancer involves surgery, chemotherapy and radiotherapy, but each type of treatment involves risks to the fetus and the pregnant woman. We present a case of a young primiparous woman who had a quick and bad evolution of an adenocarcinoma of the rectum diagnosed during pregnancy. This patient had extensive involvement of the liver with metastasis and she died two weeks after diagnosis. In this case, we present the clinical, radiological and pathology findings of this disease.
\end{abstract}

\section{Introduction}

The incidence of pregnancy-associated cancer is relatively low, complicating $0.02-0.1 \%$ of all pregnancies [1]. The most common tumors diagnosed during pregnancy are breast cancer, cervical cancer, melanoma, and leukemias/lymphomas. Lung, gastrointestinal, urological and other malignancies are rarely observed [2]. Cancer of the rectum is a very rare disease during pregnancy, with an incidence of 
1:50,000 to 1:100,000 pregnancies. However, mainly in industrialized countries where the incidence of pregnancies in advanced ages is increasing, obstetricians should be vigilant of this disease [3].

We present a case of a young primiparous woman who had a quick and bad evolution of an adenocarcinoma of the rectum diagnosed during pregnancy. In this case, we present the clinical, radiological and pathology findings of this disease.

\section{Case Report}

A 17-year-old primiparous woman was admitted to our service with fever $\left(38^{\circ} \mathrm{C}\right)$, abdominal pain, weakness and recent weight loss of $5 \mathrm{~kg}$. At general physical exam, she was discolored $(+/+4)$, eupneic and anicteric. Her weight was $66 \mathrm{~kg}$, and she reported a weight of $58 \mathrm{~kg}$ before pregnancy. The abdomen was distended and with evident vascularization (fig. 1a). The liver was enlarged, hardened and several nodules were observed. Soft edema (Godet sign) was present in the lower members (fig. 1b). The obstetric exam showed a fundal height of $14.0 \mathrm{~cm}$ and a fetal heart rate of 144 beats per minute. The laboratory exams showed $\mathrm{Hb} / \mathrm{Ht}$ of $12.7 \mathrm{~g} / \mathrm{dl} / 38 \%$, fasting glucose of $89 \mathrm{mg} / \mathrm{dl}$, $\alpha$-fetoprotein of $75.25 \mathrm{ng} / \mathrm{dl}$ and carcinoembryonic antigen of $4,487 \mathrm{ng} / \mathrm{ml}$. She was hospitalized, and $\mathrm{T} 2$-sequence magnetic resonance imaging in the coronal plane was performed, which revealed an enlarged liver, with several nodules with central hypersignal, suggestive of metastasis (fig. 2). The obstetrical scan evidenced a unique and topic pregnancy with the fetus presenting biometric parameters of 21 weeks. The fetus showed no malformations, the amniotic fluid volume was normal and the estimated fetal weight was $411 \mathrm{~g}$. The patient progressed to vomiting blood, and there was also blood in her stool. The liver biopsy confirmed infiltration by adenocarcinoma with several metastases (fig. $3 \mathrm{a}$ ). The sigmoidoscopy evidenced an ulcerative-vegetative lesion $10.0 \mathrm{~cm}$ from the anal verge; the biopsy confirmed adenocarcinoma of the rectum (fig. $3 \mathrm{~b}$ ). The patient evolved with significant abdominal pain, hypotension and cardiopulmonary arrest. Death occurred two weeks after hospitalization. Necropsy confirmed the diagnosis of adenocarcinoma of the rectum with liver metastases.

\section{Discussion}

During pregnancy a woman's body undergoes physiological changes that may make the diagnosis of several cancers more challenging [4]. Cancer of the rectum presents with different patterns of development; in some cases it is insidious and in others it quickly progresses. In our case the adenocarcinoma of the rectum led to a fulminant outcome, with the patient dying two weeks after diagnosis. It is not clear if the pregnancy can modify the course of this disease. The diagnosis of adenocarcinoma of the rectum during pregnancy usually occurs in an advanced stage, and the clinical signs are rectal bleeding, transit disorder with alternating diarrhea and constipation, meteorism, abdominal pain or anemia [5]. These symptoms usually are confused with the physiological modifications during pregnancy or hemorrhoid disease. In our case the patient had rectal bleeding and abdominal pain. The vomiting of blood probably occurred due to hepatic involvement. The treatment of cancer of the rectum during pregnancy depends on staging and some other parameters such as location, size and period of the pregnancy (first or second half). Surgery during pregnancy involves the risk of bleeding and miscarriage if done before 14 weeks [6]. Chemotherapy can be started during the second or third trimester without increased risk of fetal loss or malformation [7]. Radiotherapy is not possible during pregnancy because of the risk of lethal fetal malformation, and it should be delayed until after labor. Another risk of radiotherapy in young women is castration [8]. 
In summary, we presented a case of a fulminant outcome of adenocarcinoma of the rectum in a young pregnant woman. New studies are necessary to assess if the pregnancy induces changes in the course of this type of cancer.
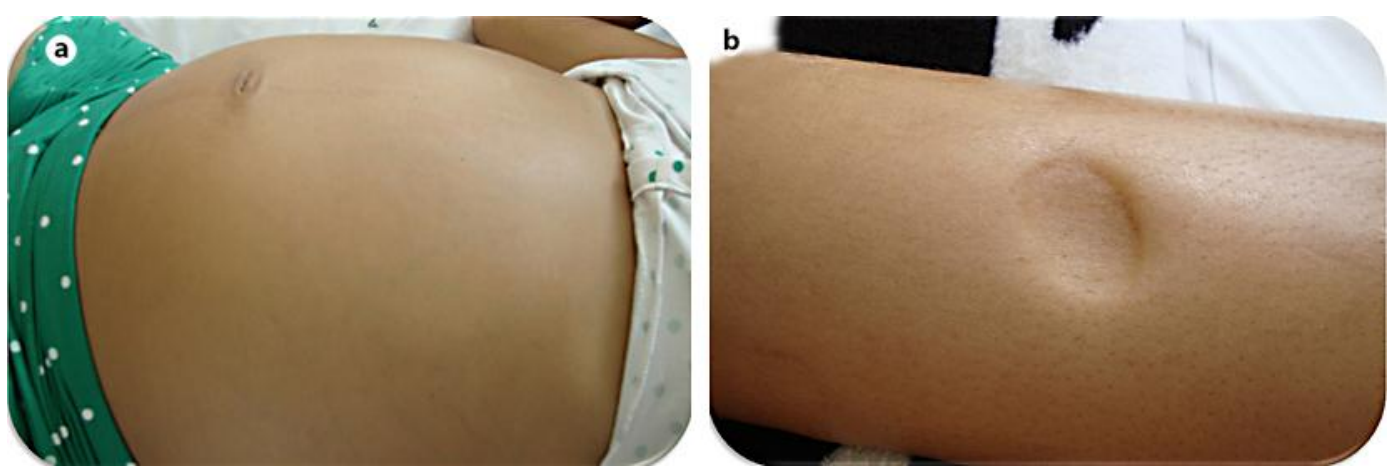

Fig. 1. a Abdominal distension with evident vascularization. b Soft edema (Godet sign) of lower members.

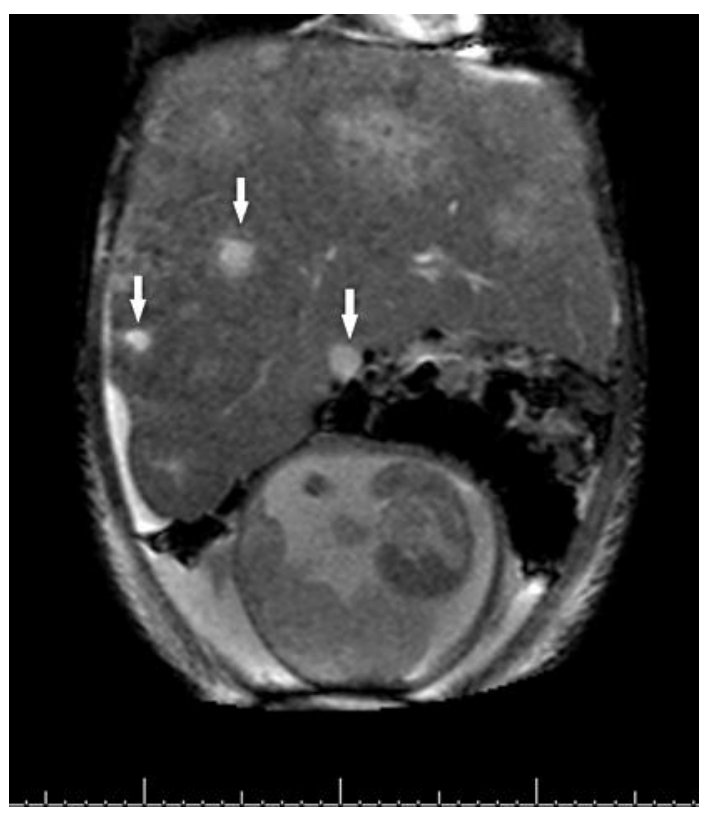

Fig. 2. T2-sequence magnetic resonance imaging in the coronal plane showing the enlarged liver with several nodules with central hypersignal (white arrows). 

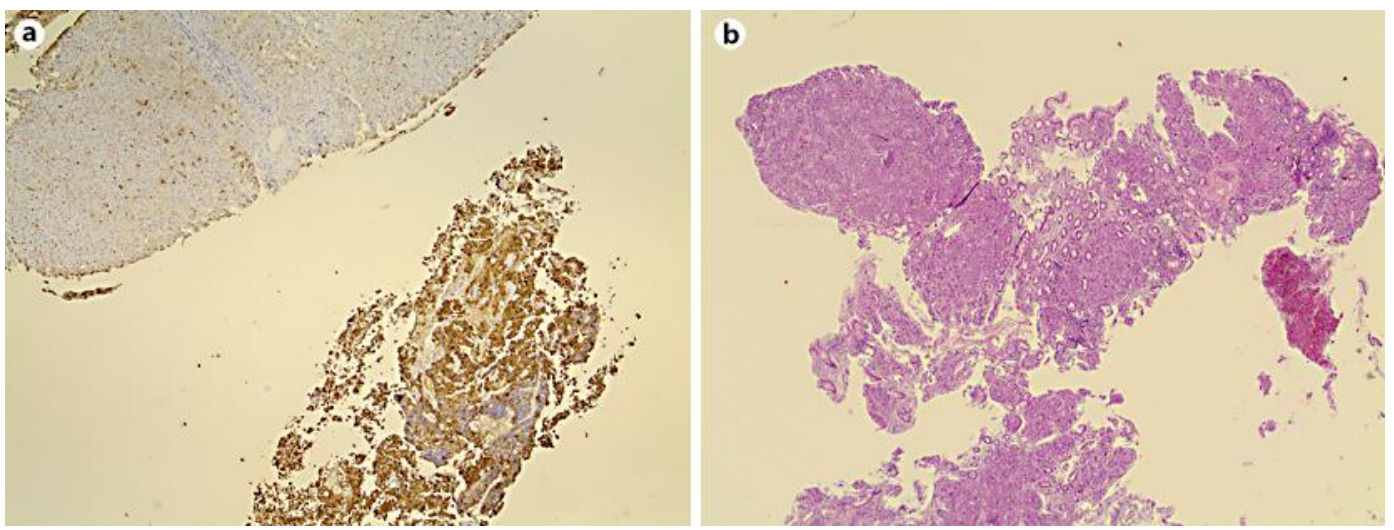

Fig. 3. a Photomicrograph of liver biopsy showing the positive immunohistochemical reaction to carcinoembryonic antigen. b Photomicrograph of rectal biopsy with hematoxylin and eosin confirming the diagnosis of adenocarcinoma.

\section{References}

1 Weisz B, Schiff E, Lishner M: Cancer in pregnancy: maternal and fetal implications. Hum Reprod Update 2001;7:384-393.

12 Pentheroudakis G, Pavlidis N: Cancer and pregnancy: poena magna, not anymore. Eur J Cancer 2006;42:126-140.

-3 Pigeau H, Dupré PF, Benouna J, Classe JM, Pioud R, Mahé MA, Dravet F: Management of rectal cancer in pregnant women [article in French]. Bull Cancer 2005;92:953-958.

-4 Pereg D, Koren G, Lishner M: Cancer in pregnancy: gaps, challenges and solutions. Cancer Treat Rev 2008;34:302-312.

5 Nesbitt JC, Moise KJ, Sawyers JL: Colorectal carcinoma in pregnancy. Arch Surg 1985;120:636-640.

6 Walsh C, Fazio VW: Cancer of the colon, rectum, and anus during pregnancy. The surgeon's perspective. Gastroenterol Clin North Am 1998;27:257-267.

7 Chourak M, Tahiri MH, Majbar A, Allala M, Najih M, Iraki H, Yaka M, Ehrichou A, Alkandry S: Colorectal cancer discovered during pregnancy [article in French]. Gastroenterol Clin Biol 2009;33:1118-1123.

8 Zinger M, Liu JH, Husseinzadeh N, Thomas MA: Successful surrogate pregnancy after ovarian transposition, pelvic irradiation and hysterectomy. J Reprod Med 2004;49:573-574. 